\title{
Faça-se luz: a revelação de um azul
}

Serão reveladas, como numa fotografia, formas e sombras de objectos vários utilizando a química do azul da prússia. Serão assim obtidos cianótipos de cor azul. Estes cianótipos serão executados sobre suportes vários, tais como papel, seda ou algodão. 0 princípio químico que aqui se demonstra tem a mesma idade que $a$ invenção da fotografia "clássica", baseada nos sais de prata. A receita utilizada na demonstração é no entanto bem mais moderna, sendo uma versão melhorada das receitas pioneiras. 0 seu autor é Michael Ware [1], que num belíssimo e recente livro relata o estado da arte do azul da prússia e seu uso nos cianótipos.

A utilização da luz para revelar sombras e formas de objectos foi utilizada durante dezenas de anos, quando ainda não existiam as modernas fotocopiadoras, para produzir cópias em ateliers gráficos, de arquitectura, etc. Foi também utilizada e continua a sê-lo para fins artísticos como, até há pouco, se pôde admirar na belíssima exposição do Grand Herbier d'Ombres de Lourdes Castro, na Fundação Calous- te Gulbenkian. Outras aplicaçōes deste processo surgirão por certo no futuro resultado do engenho e arte dos próximos descobridores.

O azul da prússia é um sólido inorgânico constituído por uma unidade básica, figura 1, em que 4 iões ferro se apresentam nos vértices de um cubo, unidos por pontes de cianeto. Os iōes ferro apresentam estados de oxidação $+2 \mathrm{e}+3$ e a cor é resultante de uma transferência de carga.

A formação de azul da prússia a partir de uma mistura de ferrioxalato e ferricianeto é devida à fotoreacção do ferrioxalato. Este degrada por acçāo da luz, com libertação de $\mathrm{CO}_{2}$ e formação de $\mathrm{Fe}(\mathrm{II})$. Este último ião envolve-se numa reacção redox com o ferricianeto existente na mistura, formando-se assim o ferrocianeto férrico que precipita. Ou seja, temos um azul revelado! Se a intensidade ou o tempo de exposição forem grandes pode formar-se branco da prússia a partir da fotoreacção do ferrocianeto férrico e o ião $\mathrm{Fe}(11)$. No entanto, com o tempo, este oxida-se a ferrocianeto férrico (azul da prússia).

\section{As reacções}

$$
2\left[\mathrm{Fe}^{\prime \prime \prime}\left(\mathrm{C}_{2} \mathrm{O}_{4}\right)_{3}\right]^{3-} \stackrel{\mathrm{hv}}{\longrightarrow} 2 \mathrm{Fe}^{2+}+2 \mathrm{CO}_{2}+5 \mathrm{C}_{2} \mathrm{O}_{4}^{2-}
$$

$$
4 \mathrm{Fe}^{2+}+3\left[\mathrm{Fe}^{\prime \prime \prime}(\mathrm{CN})_{6}\right]^{3-} \stackrel{\text { oxidação }}{\longrightarrow} \mathrm{Fe}_{4}^{\text {III }}\left[\mathrm{Fe} \mathrm{e}^{\prime \prime}(\mathrm{CN})_{6}\right]_{3}
$$

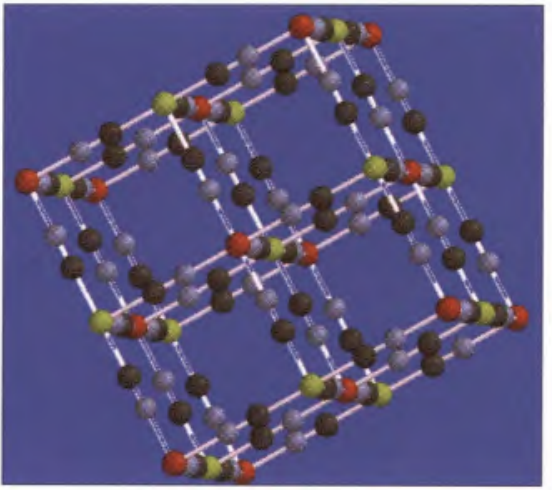

figura 1 Estrutura cristalina do azul da prússia. Iões férricos a vermelho, iōes ferroso a verde, o grupo $\mathrm{CN}$ tem os átomos de $\mathrm{C}$ a preto e os de $\mathrm{N}$ a azul. (@http://www.cator.hsc.edu/ mollusk/chemart/photo/cyanotype.html\#c4)

\section{Interesse da actividade}

Esta actividade pode ser apresentada como um espectáculo, em que como por magia, se faz aparecer o azul da prússia. Tendo assim cativado a atençāo do espectador, pode-se então revelar a Química do processo. As histórias químicas que se podem contar a partir desta experiência são ínúmeras. A história da descoberta do pigmento, azul da prússia, pode ser aproveitada quer para introduzir o conceito de serendipity em Ciência, quer para falar dos dois azuis que o precederam, o lapis lazuli e a azurite. Estes pigmentos inorgânicos acompa-

nharam o homem deste a antiguidade. A partir de finais séc. XVIII, a Química provará que é muito mais rentavel sintetizar as cores existentes na Natureza, ou ainda, produzir outras inventadas pelo homem.

Esta actividade pode também ser facilmente integrada numa aula de Química-Física onde se discutam as causas da cor, ou reacçōes fotoquímicas. Pode ser também utilizada numa aula de Química Inorgânica como complemento ou paralelamente à sintese do azul da prússia obtido, p.e., a partir de sulfato de ferro (II) e ferricianeto de potássio [4].

\section{Acerca da actividade}

É necessário alertar os estudantes para o facto de alguns dos produtos,

nomeadamante a solução final, reagirem por acção da luz; alguns dos passos desta actividade deverão ser efectuados numa sala escura.

\section{Resposta às perguntas}

1) Os reagentes presentes na solução final, por acçāo da luz, transformam-se em azul da prússia, um composto inorgânico insoluvel em água.

2) Em solução existem 2 compostos de ferro no estado de oxidação +3: o ferrioxalato de ferro e o ferricianeto. Por absorção de luz no vísivel o ferrioxalato de ferro decompōe-se, com formação de dióxido de carbono, $\mathrm{CO}_{2}$, e $\mathrm{Fe}^{2+}$; este processo envolve vários passos, podendo ser resumido na equação acima apresentada. $\mathrm{O}$ ião $\mathrm{Fe}^{2+}$ sofre uma reacçāo redox com o ferricianeto em solução, formando-se um precipitado insolúvel de azul da prússia.

\section{Outras experiências e referências}

[1] M. Ware, "Cyanotype: the history, science and art of photographic printing in Prussian blue", Science Museum and National Museum of Photography, Film \& Television, 1999.

[2]http://www.mikeware.demon.co.uk/cyano.html

[3] JCE Classroom Activity 19, J. Chem. Educ., 76 (1999) 1216

[4] M. V. Orna, J. Chem. Ed., 57 (1980) 256 


\section{Faça-se luz: a revelação de um azul}

Os cianótipos sẫo descobertos, absolutamente por acaso, em 1870, por John Herschel. 0 azul da prússia, por seu lado, também foi descoberto por puro acaso, mas quase 2 séculos antes, em Berlim, algures entre 1704 e 1705, por um certo Diesbach. Diesbach era um fabricante de tintas que, ao tentar poupar no preço de dois dos reagentes necessários à obtenção de uma laca vermelha, os comprou de tal forma impuros que obtve como resultado azul da prússia! 0 azul da prússia foi o primeiro azul de síntese da idade moderna, antes dele, fruto do engenho humano apenas conhecemos o azul Egípcio, que tal como o nome indica é devedor da civilização Egipcia, mas cujo segredo de manufactura se perdeu com a queda do Império Romano. A descoberta do azul da prússia foi um sucesso comercial, de tal forma que destronou completamente os dois azuis até aí utilizados na grande arte da pintura, a azurite e o magnifico lápis lazuli. Este último mais que uma cor, era um símbolo de majestade e riqueza, o seu preço na Idade Média era comparável ao do ouro e mesmo assim nem todos os artistas na Europa, ainda que para tal tivessem posses, o conseguiam comprar!

Um cianótipo é uma fotografia em que a revelação se faz com a formação do azul da prússia. A palavra cianótipo é composta por ciano-,
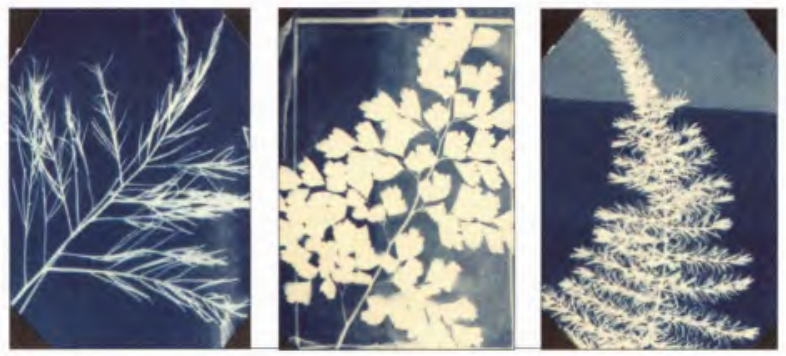

\section{Preparação das soluções}

1) Solução a $25 \%$ de dicromato de amónio: para um copo ou erlenmeyer de $20 \mathrm{ml}$ pese $2,5 \mathrm{~g}$ de sólido e perfaça com água destilada para um volume final de $10 \mathrm{ml}$.

2) Moa num almofariz $5 \mathrm{~g}$ de ferricianeto de potássio.

3) Num erlenmeyer de $50 \mathrm{ml}$, coloque a aquecer $\mathrm{a}=50^{\circ} \mathrm{C}$, cerca de $15 \mathrm{ml}$ de água destilada.

nota: o restante procedimento deverá ser feito num local escuro, ao abrigo da luz, de preferência numa câmara escura com luz vermeIha.

4) A solução aquosa obtida em 3), adicione $15 \mathrm{~g}$ de oxalato de ferro(III) amoniacal, agite bem para dissolver; seguidamente adicione 0,25 ml da soluçăo a $25 \%$ de dicromato de amónio. Por fim, adicione lentamente o ferricianeto de potássio finamente moído e agite bem.

5) Deixe a solução a repousar, ao abrigo da luz, por cerca de 1 h.

6) Filtre ou decante para um erlenmeyer de $100 \mathrm{ml}$; deverá obter cerca de $15 \mathrm{ml}$ de solução. Perfaça a cerca de $100 \mathrm{ml}$ por adiçẫo de água destilada. Se desejar pode diluir mais. Esta solução é o ingrediente base para o fabrico dos cianótipos. 0 pó que precipitou é ferrioxalato de potássio. Se tiver um colega fotoquímico pode oferecer-Ihe o pó, cuidadosamente resguardado da luz, por certo o fará feliz!

A solução obtida tem uma cor verde azeitona, bastante escura, e é extremamente fotosensivel, como tal deverá ser guardada num frasco escuro, de preferência embrulhado em papel de alumínio, para impedir completamente a entrada de radiação luminosa. do grego $\kappa u \alpha v \varepsilon o \zeta$, que designa uma cor escura, possivelmente um azul escuro, e por -tipo, do grego $\tau u \pi o \zeta$, impressão. Este pigmento é um sólido inorgânico de ferrocianeto férrico. Ou seja, os iões ferro encontram-se em 2 estados de oxidação, +3 e +2 , unidos por pontes de cianeto. A magnífica e intensa cor que apresenta é resultado do movimento de um electrão entre um ião $\mathrm{Fe}^{2+}$ e um ião $\mathrm{Fe}^{3+}$

A técnica dos cianótipos teve extensa utilização em ateliers gráficos, de arquitectos e outros; foi utilizada para produzir fotocópias, num tempo onde ainda não existiam as nossas actuais máquinas fotocopiadores. Para além disso, foi desde muito cedo utilizada em substituição da fotografia clássica com sais de prata. Anna Atkins utilizou-a para produzir magnificos herbários, que publicou em Inglaterra durante as últimas décadas do século XIX. Muitos destes cianótipos encontram-se conservados no British Museum, tendo-se podido constatar que como material o seu tempo de vida é de longe superior à fotografia clássica.

Os cianótipos são também uma técnica muito versátil, uma vez que permitem uma impressāo em suportes vários, como por exemplo, o papel, algodão e a seda.

\section{Experimente}

Para esta experiência necessita do seguinte material: dois erlenmeyers de $50 \mathrm{ml}$ e um de $100 \mathrm{ml}, 2$ copos de pirex de $20 \mathrm{ml}, 1$ proveta de $20 \mathrm{ml}, 1$ pipeta de $1 \mathrm{ml}, 1$ almofariz, espátulas e balança com precisão às casas decimais. Por fim necessita um frasco opaco para guardar a solução final.

Os produtos necessários são: oxalato de ferro (III) amoniacal, $\left(\mathrm{NH}_{4}\right)_{3}\left[\mathrm{Fe}\left(\mathrm{C}_{2} \mathrm{O}_{4}\right)_{3}\right] .3 \mathrm{H}_{2} \mathrm{O}$; ferricianeto de potássio, $\mathrm{K}_{3}\left[\mathrm{Fe}(\mathrm{CN})_{6}\right]$; dicromato de amónio, $\left(\mathrm{NH}_{4}\right)_{2} \mathrm{Cr}_{2} \mathrm{O}_{7}$ e água destilada. Lâmpada de 300 ou 100 Watts, ou ainda luz do sol

\section{Realização da experiência}

Existem mil e uma formas de impregnar o seu suporte; por isso pode utilizar a sua imaginaçāo e engenho se não the agradar a alternativa que propomos. Basta que saiba que para obter um azul muito escuro, é necessário aplicar cerca de $1,5 \mathrm{ml}$ de sensibilizador numa área de 25 por $20 \mathrm{~cm}$; ou seja, aproximadamente a área de uma folha A4 em que se deixa uma margem confortável. A aplicação pode ser feita com a ajuda de um pincel; para ajudar a secar pode utilizar um secador de cabelos ou pode optar por deixar o papel ou tecido secarem por si. Se optar por esta solução guarde-os num armário ao abrigo da luz. As folhas tratadas com o sensibilizador podem ser utilizadas logo que secas, ou podem ser guardadas, numa caixa absolutamente opaca. Uma variante do revestimento do papel, consiste em misturar a solução sensibilizadora com uma cola à base de poli(acetato de vinilo), p.e, a cola Sabu à venda na Casa Ferreira.

Coloque sobre o papel as formas que deseja ver reveladas, podem ser folhas secas, penas, pedaços de rede, papéis recortados, etc, etc: para obter uma imagem mais nitída é conveniente que coloque um vidro por cima desse objectos.

Finalmente, faça-se luz! Com uma Lâmpada de 300 Watts da Osram ou luz do sol bastam uns poucos minutos, 3-5 minutos, com uma lâmpada mais comum, de $100 \mathrm{~W}$, de 5 a 10 min; se deixar o cianótipo tempo demais a ser revelado poderá obter branco da prússia! No entanto, nâo desepere, pois em contacto com o ar, lentamente, reaparecerá a magnífica cor do azul da prússia!

\section{Para responder}

1) Explique porque se deve guardar a solução final ao abrigo da luz.

2) Explique a que se deve o aparecimento da cor azul após exposição à luz. 